\title{
Prevalence and Geographical Distribution of Precancerous Lesions of the Uterine Cervix in Cameroon
}

Tebeu Pierre Marie ${ }^{1,2 *}$, Zachari Sando ${ }^{3}$, Alice Ndoumba1, Isaac Sandjong ${ }^{1}$, Paulette Mawech-Fauceglia ${ }^{4}$ and Anderson Sama Doh ${ }^{1}$

${ }^{1}$ Department of Gynaecology \& Obstetrics, University Hospitals, Yaoundé, Cameroon

${ }^{2}$ Initiative League and Active Research for Health and Education of Women, Cameroon

${ }^{3}$ Department of Clinical Pathology, University Hospitals Yaoundé-Cameroon

${ }^{4}$ Department of Gynecologic Pathology, University of Southern California, Los Angeles, CA, USA

\section{Abstract}

Objective: The aim of this study is to determine the prevalence of cervical precancerous lesions in Cameroon.

Methods: A cross-sectional study for one year period has been conducted in 6 regions of Cameroon by the National Cancer control Committee and the Gynecologic and Pediatric Hospital in Yaoundé from 1/1/2009 to 12/30/2009.

Results: Women were diagnosed of precancerous cervical lesions (97/2485), making the national prevalence of $3.9 \%$, with the highest rate located in Centre, Littoral and Far North regions. The age of the affected women was $27-55$ years with $67 \%$ women between 34 and 49 years old. The majority of these women had at least four pregnancies (32\%).

Conclusion: The prevalence of precancerous lesions of the uterine cervix in Cameroon varies among regions depending on the existence of screening activities. Continuing effort in extending these programs in different regions will make a noticeable improvement in preventing cervical cancer.

Keywords: Cervical cancer; Screening; Precancerous lesion; Cameroon

\section{Introduction}

Cervical cancer is a major public health issue in Cameroon $[1,2]$. Uterine cervical cancer accounts for $23.2 \%$ of all female malignancies, and it is considered to be the second most common gynecological cancer in Cameroon [3]. Due to the diagnosis of uterine cervical cancer at advanced stage, it is considered to be the leading death among women of Cameroon [4]. The existence of precursor lesions for invasive cervical cancer has been recognized for more than half a century. Once the concept of carcinoma in situ was accepted as a precursor of invasive cervical cancer, a population-based cytology screening programs were conducted to detect and to treat pre-invasive lesions before they progress to invasive cancer. The cytology screening program was a very successful approach where it is estimated to reduce death rates from cervical cancer of about $50 \%$ (14.2 to 7.8 per 100,000 women) in the United States of America from 1973 to 1994 [5]. Despite the progress that has been made in preventing invasive cancer by adopting cytology screening program, cervical cancer remains to be the leading cause of female death and it still constitutes a major health problem. Despite the presence of many literature on precancerous lesions of the uterine cervix in Cameroon [6], data of its occurrence, geographical distribution and epidemiological characteristics is still missing. These data would be very helpful in planning national and regional strategies to fight against cervical cancer.

\section{Objective}

The aims of this study are to determine the prevalence of precancerous lesions of uterine cervical cancer in Cameroon and to define their geographic distribution in different regions of this country.

\section{Methods}

This is a descriptive cross sectional study-evaluating women who participated in the screening campaigns for one year period from $1 / 1 / 2009$ to $12 / 30 / 2009$. The criteria for exclusion were pregnancy, women in her menstrual cycle, and women with total hysterectomy/ radiotherapy and or conization prior her enrollment in our study. The age ranged from 25 to 55 years old. The study evaluated data from the National Committee of "Fight against Cancer" and from the pathology laboratory at the Gynecologic Obstetric and Pediatric Hospital of Yaoundé. Campaign of screening and management of cervical premalignant lesions were conducted at different health facilities including the Centre region (Hospital of Bafia, Gynecologic Obstetric and Pediatric Hospital, District Hospital of "Cité Verte", mobile Units in Melen at the Faculty of Medicine), the South Region (Sangmélima, Ebolowa, Meyomessala and Ndonkol Hospitals), the West Region (Regional Hospital of Bafoussam, Bafang and Baham District Hospitals), the North-West Region (Bamenda and Bali Hospitals), the Littoral Region (Laquintinie Hospital) and the Far North Region (Maroua Regional Hospital). Women with positive cytology-based (Papanicolaou smear) were confirmed by histologic diagnosis on cervical biopsy. The criteria for exclusion were pregnancy, women in her menstrual cycle, and women with total hysterectomy/radiotherapy and or conization prior her enrollment in our study.

Data were collected on a pre-established standard questionnaire. Geographic screening areas, age, parity and gravidity were considered as variables. Data analysis was performed using the software EPI Info 3.5.1. The Figures were drafted with the software Excel. The qualitative data have been represented as proportion and quantitative data as mean.

${ }^{*}$ Corresponding author: Pierre Marie Tebeu, Department of Obstetrics and Gynaecology, Faculty of Medicine and Biomedical Sciences, University Hospital, Yaoundé- Cameroon, Tel : ++ (237) 776755 33; E-mail: pmtebeu@yahoo.fr

Received August 19, 2013; Accepted August 25, 2013; Published September 03, 2013

Citation: Tebeu PM, Sando Z, Ndoumba A, Sandjong I, Mawech-Fauceglia P, et al. (2013) Prevalence and Geographical Distribution of Precancerous Lesions of the Uterine Cervix in Cameroon. J Cytol Histol 4: 183. doi: 10.4172/21577099.1000183

Copyright: (C) 2013 Tebeu PM, et al. This is an open-access article distributed under the terms of the Creative Commons Attribution License, which permits unrestricted use, distribution, and reproduction in any medium, provided the original author and source are credited. 


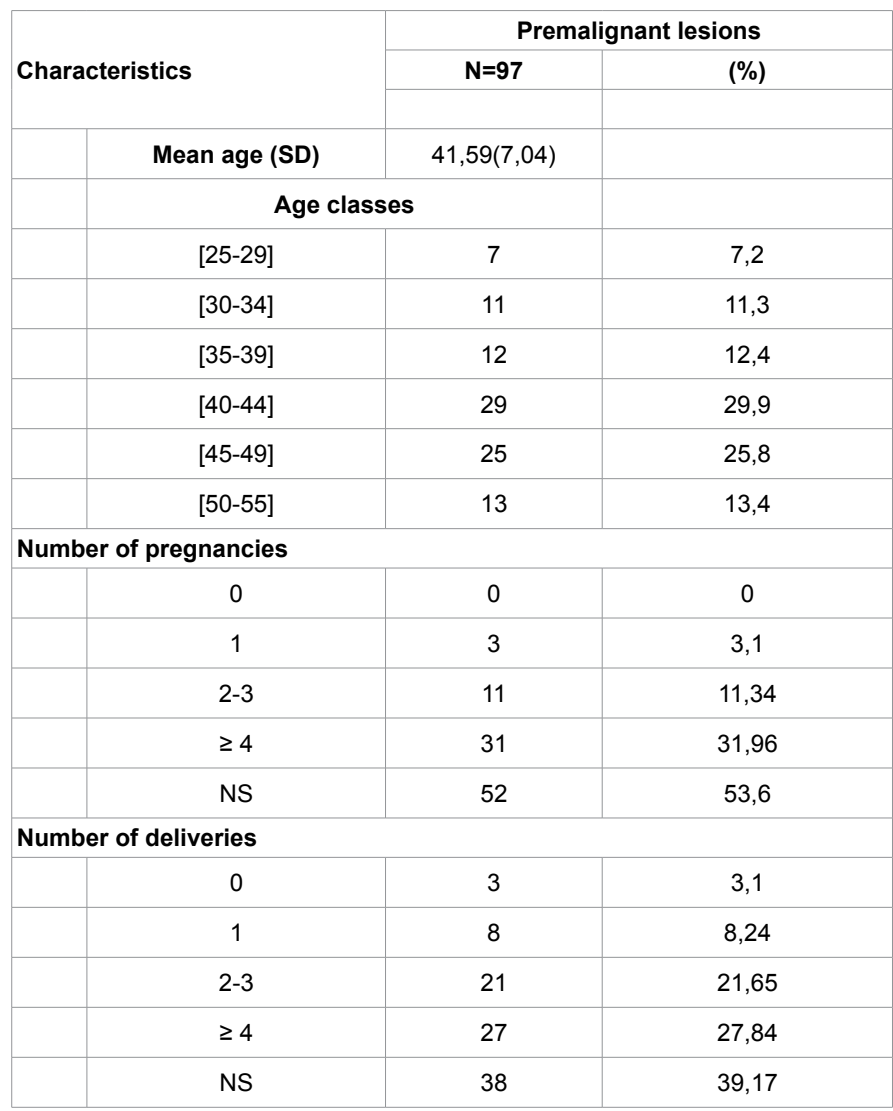

SD Standard Deviation; \% percentage; NS Non specified

Table 1: Characteristic of women with precancerous lesions of the uterine cervix.

\begin{tabular}{|c|c|c|c|c|c|c|c|}
\hline \multirow{3}{*}{$\begin{array}{l}\text { Regions of } \\
\text { screening }\end{array}$} & \multirow{3}{*}{$\begin{array}{l}\text { Screened } \\
\text { women }\end{array}$} & \multicolumn{4}{|c|}{ Histology } & \multirow{2}{*}{\multicolumn{2}{|c|}{ Total }} \\
\hline & & \multicolumn{2}{|c|}{ CIN 1} & \multicolumn{2}{|c|}{$\operatorname{CIN} 2 / 3$} & & \\
\hline & & $\mathrm{n}$ & $\%$ & $\mathrm{n}$ & $\%$ & $\mathrm{n}$ & $\%$ \\
\hline Centre & 818 & 20 & 2,5 & 21 & 2,5 & 41 & 5,01 \\
\hline West & 584 & 8 & 1,36 & 9 & 1,5 & 17 & 2,91 \\
\hline North West & 483 & 5 & 1,03 & 0 & 0 & 5 & 1,03 \\
\hline South & 230 & 1 & 0,4 & 6 & 2,6 & 7 & 3,04 \\
\hline Far North & 207 & 9 & 4,3 & 6 & 2,9 & 15 & 7,24 \\
\hline Littoral & 163 & 10 & 6,1 & 2 & 1,2 & 12 & 7,36 \\
\hline Total & 2485 & 53 & 2,1 & 44 & 1,8 & 97 & 3,9 \\
\hline
\end{tabular}

Table 2: Geographic distribution of precancerous lesions in women of Cameroon.

\section{Results}

During the study period, 680 out of 3165 women who participated in the cervical cytology screening program were excluded due to our set criteria for exclusion. Ninety seven out of the remaining 2485 women (3.9\%) were diagnosed of cervical precancerous lesions and the diagnosis was confirmed by histology on cervical biopsy. The sociodemographic characteristic of the women with precancerous lesions are presented in the Table 1. The geographic distribution of women with precancerous lesions is illustrated in Table 2. High prevalence $(>5 \%)$ was found in the Center, the Far North and the Littoral regions. Whereas, intermediate prevalence $(2-5 \%)$ were located in the west and the South regions, and low prevalence $(<2 \%)$ in the North West region.

\section{Discussion}

The prevalence of precancerous lesion of the uterine cervix in
Cameroon is similar to that reported in 1992 in Burkina Faso, West Africa (4.2\%) [7]. However, data from other countries reported a higher prevalence rate such as at $16.4 \%$ and $34.8 \%$ in HIV negative and HIV positive women respectively in Central African republic Africa [8]. In the present study, patients were not tested for HIV. In developed countries as France, the prevalence rate is much lower at around of $0.5 \%$. The difference of prevalence of the precancerous lesions of the uterine cervix from one country to another is mainly due to the existence and consistency of screening programs and management options implemented in these countries.

Their age ranged from 27 to 55 years with a mean age of 41.59 years (SD: 7.04 ) and $67 \%$ of women were between the ages of $34-49$ years. Therefore, if we intend to start a population-based screening program in different regions of Cameroon, it would be rational to limit our screening to 34-49 years age group. Our findings are in concordance with the WHO recommendations for cervical screening program in countries without previous program that is in order for women to benefit of a screening program, it is necessary to target those of 35 to 45 years age group [9]. The mean number of deliveries for women with precancerous lesions of the uterine cervix was three childbirths and those with more than 3 deliveries represented 32\%. Multiparity in women with precancerous cervical lesion was previously seen in Burkina Faso, West Africa [8]. These data lead to suggest the possibility of an association between multiple childbirths and cervical premalignant lesions in Cameroon

Among the 97 women with premalignant lesions, the percentage of low grade dysplasia (cervical intraepithelial neoplasia grade 1(CIN 1)) was $54 \%$ and high grade dysplasia (CIN 2-3) was $46 \%$.

The regions of highest prevalence rate $(>5 \%)$ included the regions of the Littoral, the Far North and the Center, the regions of intermediate prevalence rate (consisted of the regions of the West and the South and the region of low prevalence rates was that of the North-West region. These results are in accordance with a previous study conducted in 2001 that revealed a $7 \%$ prevalence rate in the Littoral and Center regions. This high prevalence rate could mainly be explained by the lack of consistency in implementing screening programs in these regions of the country. Even though the overall prevalence rate of precursor cervical lesions remains constant (2-5\%) in the regions of the South and West, there is a constant decline of high grade dysplasia such as $2.5 \%$ in 2002 , $2 \%$ in 2005 and $1.5 \%$ in the present study [10]. This decline could be related to at least two previous screening campaigns conducted by the National Committee for "Fight against Cancer" within the last 5 years. Finally, the reason of low prevalence rate in the Northwest could be attributed to the presence of several effective screening campaigns [11].

\section{Conclusion}

Our findings give us a great insight of the precancerous lesions in different regions of Cameroon and they confirm the need of continuing active screening campaigns in this country. We hope that with continuous efforts we can lower the death rate of cervical cancer among the women of Cameroon.

\section{References}

1. McCarey C, Pirek D, Tebeu PM, Boulvain M, Doh AS, et al. (2011) Awareness of $\mathrm{HPV}$ and cervical cancer prevention among Cameroonian healthcare workers. BMC Womens Health 11: 45.

2. Berner A, Hassel SB, Tebeu PM, Untiet S, Kengne-Fosso G, et al. (2013) Human papillomavirus self-sampling in Cameroon: women's uncertainties over the reliability of the method are barriers to acceptance. J Low Genit Tract Dis 17: $235-241$. 
Citation: Tebeu PM, Sando Z, Ndoumba A, Sandjong I, Mawech-Fauceglia P, et al. (2013) Prevalence and Geographical Distribution of Precancerous Lesions of the Uterine Cervix in Cameroon. J Cytol Histol 4: 183. doi: 10.4172/2157-7099.1000183

3. Enow Orack GE, Ndom P, Doh AS (2008) Cancer Incidence in Cameroon. Yaound $\tilde{A} \odot$ Cancer registry.

4. Tebeu PM, Petignat P, Mhawech-Fauceglia P (2009) Gynecological malignancies in Maroua, Cameroon. Int J Gynaecol Obstet 104: 148-149.

5. Robles SC, White F, Peruga A (1996) Trends in cervical cancer mortality in the Americas. Bull Pan Am Health Organ 30: 290-301.

6. Doh AS, Kouam L (1999) The management of pre-invasive cervical lesions using cryotherapy in Yaounde, Cameroon. J Obstet Gynaecol 19: 640-642.

7. Soudre B, Lamien TO, Sanou M, Sankande BL (1992) Cervical premalignant lesions of the uterine cervix in Burkina; cytologic study in two Provinces ( Oudalan, Seno ) Med Afr Noire 39: 806-900.
8. Solve B Lamien TO, Kone B, M Sanou, Sankande BL (1992) of the precancerous uterine collar in Burkina, to study cytological actual Alisa in two provinces (Oudalan SÃ @ no). Med Af N 39: 806-900.

9. WHO. DÃ $\odot$ cancer screening Cervical Uterine $(\subset)$ rus. In: WHO editor. The fight against cancer of the cervix Uterine (c) rus. Guide to essential practice. p. 83-133.

10. Robyr R, Nazeer S, Vassilakos P, Matute JC, Sando Z, et al. (2002) Feasibility of cytology-based cervical cancer screening in rural Cameroon. Acta Cytol 46: $1110-1116$.

11. Tebeu PM Nkele N, S Fokoua, Sandjong DI, Achu P (2002) Prevalence of precancerous lesions of the uterine cervix in Cameroon. If Bali (North West). Cameroon Journal of Medicine 11: 32 